\title{
Brief period of post-encoding wakeful rest supports verbal memory retention in children aged $10-13$ years
}

\author{
Markus Martini ${ }^{1} \cdot$ Caroline Martini $^{1} \cdot$ Pierre Sachse $^{1}$
}

Published online: 9 February 2019

(C) The Author(s) 2019

\begin{abstract}
Evidence exists that a brief period of wakeful rest after learning can support the retention of memories, whereas a period filled with a cognitive task after learning can weaken the retention of memories. The present study in 10-13 year old children investigated whether wakeful resting after encoding is more beneficial for the retention of new verbal information than watching movies, which reflects a common everyday life/learning break activity in children at this age. Children encoded a word list. After immediate recall of this word list, they wakefully rested for $12 \mathrm{~min}$. Next, children encoded another word list. After immediate recall of this word list, they watched animated short movies for $12 \mathrm{~min}$. The order of the delay conditions (rest, movies) was counterbalanced across children. At the end of the experimental session, a surprise free recall test took place. Overall analyses revealed that while memory performance decreased over time in both the resting condition and movies condition, it decreased significantly more in the movies condition. These results indicate that wakeful resting supports the retention of verbal information in children aged $10-13$ years.
\end{abstract}

Keywords Wakeful resting $\cdot$ Memory retention $\cdot$ Retroactive interference $\cdot$ Memory consolidation $\cdot$ Children

\section{Introduction}

Studies indicate that memory retention can be significantly affected by the activity directly after learning (e.g. Dewar et al. 2012, 2007; Craig et al. 2015; Mercer 2015; Brokaw et al. 2016). Already Bigham (1894) found that younger adults showed less forgetting when the interval between learning and recall was 'unfilled' compared to processing a cognitively demanding distractor task. This view was extended by Müller and Pilzecker (1900) showing in adults that a shorter temporal separation between two learned word lists led to a lower recall performance for the first word list. However, these findings were offset with a higher temporal separation between the two word lists (see also Brown et al. 2007). Recent research efforts delineated the impact of a cognitive

Electronic supplementary material The online version of this article (https://doi.org/10.1007/s12144-019-0156-0) contains supplementary material, which is available to authorized users.

Markus Martini

markus.martini@uibk.ac.at

1 University of Innsbruck, Innrain 52, 6020 Innsbruck, Austria task delay period from a resting period after learning, defined as a state of low external stimulus input and task-related interference. The majority of these studies indicate that resting (eyes closed, relaxed) after learning supports memory retention more than a cognitive task delay period (Cowan et al. 2004; Dewar et al. 2007; Craig et al. 2015).

The reasons why wakeful resting supports memory retention has not been fully understood yet. Neuroscientific evidence exists that task-relevant brain areas stay active during post-encoding wakeful rest. These studies showed that activity and connectivity of those brain areas, which were also involved during learning, predicted (interindividual differences in) subsequent memory performance (e.g. Tambini et al. 2010; Schapiro et al. 2018). It is assumed that during periods of wakeful rest recent events are neurally 'replayed' (Deuker et al. 2013; Staresina et al. 2013; Dudai et al. 2015; Peigneux et al. 2006; Schapiro et al. 2018), which helps memories to get consolidated, i.e. to be transformed into longerlasting, more stable memories less prone to interference (Robertson 2012; Deuker et al. 2013).

The majority of wakeful resting studies investigated healthy younger and older adults as well as patients with neurological diseases showing supporting effects of wakeful resting over shorter (minutes) and longer 
(days) retention delays with different learning material and post-learning cognitive filler tasks (Brokaw et al. 2016; Cowan et al. 2005; Della Sala et al. 2005; Dewar et al. 2007, 2012; Craig et al. 2015; Mercer 2015).

Only a few studies investigated the impact of a brief period of wakeful rest on memory in children. Studies showed that memory and memory consolidation develop across lifespan (Gathercole 1998; Wilhelm et al. 2012). For instance, the number and details of memories that can be maintained over short temporal intervals increase as children grow older (see Hertzog and Shing 2010). From sleep studies, it is known that long-term memory performance is positively affected by the time spent in specific sleep states (e.g. non-rapid eye movement sleep) and brain activity during this state (e.g. slow oscillatory activity) (Henderson et al. 2012, 2013; Wilhelm et al. 2008; Backhaus et al. 2008; Kurth et al. 2010; Ohayon et al. 2004). Based on this view, it stands to reason that age-related differences in the impact of a brief period of resting exist. Fatania and Mercer (2017) conducted a wakeful resting study in children (age 6-7 years) and adults (age 18-61 years). They found that children recalled more words in a delay condition, where they had to remain quiet for $5 \mathrm{~min}$ after learning, than in a delay condition, where they had to complete spot-the-difference puzzles after learning. Adults recalled more words than children in both delay conditions but showed no differences between the delay conditions (for similar findings in adults see Varma et al. 2017; Martini et al. 2017; see also Darby and Sloutsky 2015). In a second experiment in 6-7 year old children only, they found no differences between the wakeful resting condition and spot-thedifference condition, provided that children were given more time to learn and recall a word list. These results indicate that an increase in learning and recall times reduces the impact of post-learning interference (but see Bauer et al. 1999). Thus, resting may be especially important for children under suboptimal learning conditions or maybe similar between different delay conditions if one assumes generally weaker encoding strength in children. This view is supported by a recent study in children aged 13-14 years (Martini et al. 2018a). Martini et al. (2018a) showed that a 10-min post-encoding wakeful rest phase supported memory retention over 7 days, but only in children showing a lower immediate memory performance.

In order to further specify conditions under which wakeful resting supports memory in children of different ages the present study with children aimed at investigating whether a brief period of wakeful rest after learning supports memory retention more than a period of task-related cognitive processing (Fatania and Mercer 2017, Experiment 1). In extension to previous wakeful resting studies (Fatania and Mercer 2017; Dewar et al. 2012; Craig et al. 2015; e.g. Cowan et al. 2004), we (i) investigated children aged 10-13 years and (ii) implemented a delay task close to everyday life, namely watching short movies, as this is one of the top online activities in children's internet usage (GSMA 2014; Ofcom 2017). Our study design was based on the design used in previous studies in children and adults in the field (Dewar et al. 2012, 2014; Craig et al. 2015; Fatania and Mercer 2017). Children were asked to encode two word lists. After the immediate recall of one word list, they were required to wakefully rest for $12 \mathrm{~min}$ or watch animated short movies. At the end of the experimental session, a delayed free recall test took place. Based on the findings discussed above (Fatania and Mercer 2017; Dewar et al. 2012; Mercer 2015; Brokaw et al. 2016; Craig et al. 2015), we assumed to find that resting after learning supports memory retention more than watching movies.

\section{Material and Methods}

Participants Twenty-four children took part in the experiment (12 female; mean age $=11$ years, age range $=10-13$ years $)$. Children were recruited in a local school, whose headmaster confirmed willingness to support the study. Parents of children who agreed to participate gave written informed consent. Investigation of this specific age group resulted from children's and parents' readiness to take part in the study.

Materials and Procedure Figure 1 illustrates the experimental procedure (Dewar et al. 2012). Children went through two learning phases. Each learning phase consisted of (i) encoding a list of words, (ii) immediate free recall of the word list, and (iii) $12 \mathrm{~min}$ of wakeful resting or watching three animated short movies. Order of the delay conditions (rest, movies) was counterbalanced across children, i.e. word list 1 was followed by resting and word list 2 was followed by movies for half of the children (order $1 ; n=12$ ), whereas word list 1 was followed by movies and word list 2 was followed by resting for the other half (order $2 ; n=12$; Fig. 1).

The two word lists were taken from the Verbal Learning and Memory Test (Helmstaedter et al. 2001). Each word list consisted of 15 mono- and bi-syllabic nouns. Words were semantically unrelated within the word list and between the word lists. Words were presented sequentially in the middle of the screen for $1000 \mathrm{~ms}$. In between word presentation, a blank screen was presented for $1000 \mathrm{~ms}$. Children were instructed to memorize the words as accurately as possible and to immediately recall them in any order they wanted when a picture of a writing hand was presented on the screen $1000 \mathrm{~ms}$ after the last word of the word list (remained on screen for $1 \mathrm{~min}$ ). Words were noted in written form on a blank sheet of paper (one for each word list) with a time constraint of 1 min per word list (Ecker et al. 2015b). No feedback of correctly recalled words was given. After the immediate free recall, children either rested wakefully or watched three animated short movies. Both delay conditions had the same length of about 12 min. During the resting phase, children were asked to relax quietly with their eyes closed. As in previous work (e.g. 


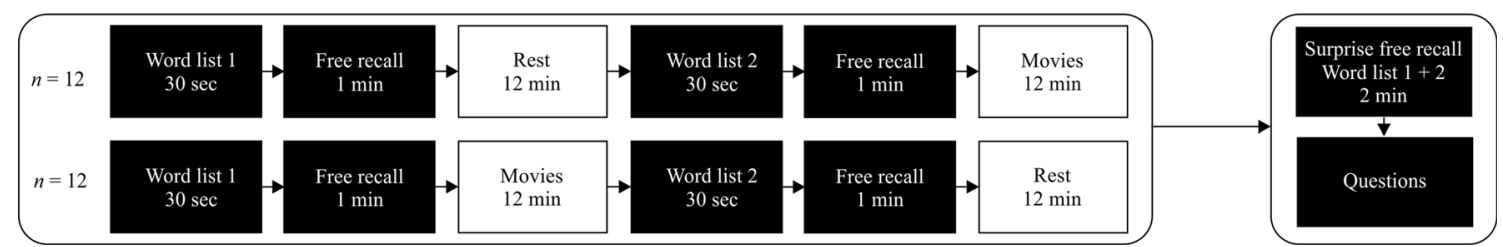

Fig. 1 Experimental procedure. Each children learned two word lists. Each word list was followed by an immediate free recall. After the immediate recall, children either rested or watched three movies for

Dewar et al. 2012), the experimenter turned off the light to provide conditions of minimal sensory input and task engagement. The experimenter rested together with the children and did not leave the room to ensure that children were not active during the resting phase. In the movies condition, children were required to watch three short 'Minions' movies. We used movies that are simple and easy to understand, while telling a complete story including a fast sequence of changing scenes within $\sim 4$ min. All movies were watched at full length. Each encoding condition (rest, movies) was preceded by a clear instruction about the encoding, recall, and delay phase. Presentation and recall were tested with children in a practice trial with five words semantically unrelated to the two word lists in the main experiment.

After the two learning phases, a surprise delayed free recall test took place. Children were asked to write down as many words as possible from the two previously learned word lists. Children noted them in any order they wanted (Dewar et al. 2012) on a blank sheet of paper within a time constraint of $2 \mathrm{~min}$. The delayed recall test was followed by postexperimental questions on rehearsal behavior during the rest and movies condition (from $1=$ 'not at all' to $5=$ 'very often'), expectation of a surprise delayed free recall test (yes/no), motivation to take part in the experiment (from $1=$ 'not at all' to $7=$ 'very much') and motivation to show a good memory performance (from $1=$ 'not at all' to 7 = 'very much').

Scoring Children received one point for each correctly recalled word. Based on previous studies (e.g. Dewar et al. 2012; Varma et al. 2017), we calculated a retention score for each child to examine how much of the immediately recalled words were retained over the delay in each condition (resting, movies). We calculated the retention score by dividing the number of correctly recalled words in the delayed recall test by the number of correctly recalled words in the immediate recall test.

\section{Results}

Figure 2 shows the number of correctly recalled words for immediate and delayed recall in the rest and movies condition. Descriptive statistics can be found in Table 1 . about 12 min followed by a surprise free recall test and postexperimental questions. Post-encoding conditions were counterbalanced across children (order group 1 and 2)

A mixed ANOVA with condition (memory retention in the rest vs. movies condition) as within-subject factor and order of the conditions (rest then movies; movies then rest) as between-subjects factor was conducted. The analysis revealed a significant main effect of condition, $F(1,22)=9.82, p<.005$, $\eta^{2}=.260$, and a significant condition*order interaction, $F(1,22)=5.88, p=.024, \eta^{2}=.156$. The main effect of order was non-significant, $F(1,22)=.16, p=.690$. Based on the significant condition*order interaction, we ran separate repeated measures ANOVAs. Results revealed no significant differences in memory retention when the rest condition was followed by the movies condition, $F(1,11)=.232, p=.639$ (Table 1). However, when the movies condition was followed by the rest condition children retained about $36 \%$ more words in the rest condition, $F(1,11)=16.79, p=.002, \eta^{2}=.604$.

Simple effects analyses of immediate memory performance (Table 1) revealed no difference between the rest and movies condition, $t(23)=.18, p=.856$. More words were recalled from the second word list than the first word list, $t(23)=$ $-2.22, p=.036, d=-.45$. Children in the respective order condition recalled a similar amount of words from word list $1, t(22)=-.97, p=.342$, and word list $2, t(22)=-1.12$, $p=.273$. The effect of higher correctly recalled words from the second word list disappeared when order-specific analyses were conducted (rest then movies condition: $t(11)=-1.56$, $p=.147$; movies then rest condition: $t(11)=-1.54$, $p=.153$ ). Analyses of our data on a non-parametric level did not change our findings (see supplemental material).

Analyses of the post-experimental questions revealed that motivation of taking part in the experiment $(M=5.04$, $S D=.81)$ and showing a good memory performance $(M=$ $5.29, S D=1.52)$ was high. Children rehearsed words to a similar low extent during resting $(M=1.79, S D=1.10)$ and watching movies $(M=1.54, S D=1.02), t(23)=.97, p=.341$, $d=.194$. Six children expected a delayed recall test. Controlling for these children by excluding them from analyses did not change our results. Spearman correlations between the post-experimental questions and immediate and delayed recall performances revealed low, non-significant relations in the rest and movies condition, $p$ 's $>.20$, except for a positive correlation between the expectation of a surprise free recall test and delayed recall performance in the movies condition, $r=.491, p=.015$. 
Fig. 2 Number of correctly recalled words ( $\max =15$ words per word list). Plotted separately for recall time (immediate, delayed) and post-encoding condition (rest, movies). Error bars represent standard errors of the mean

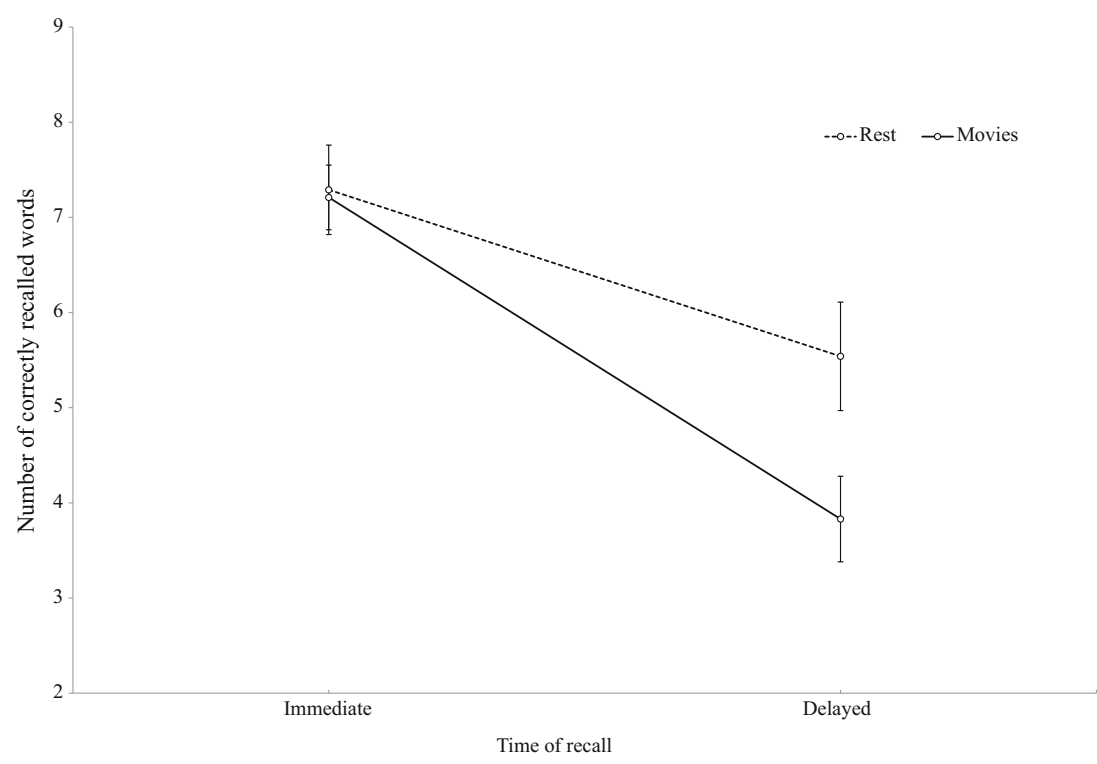

\section{Discussion}

Various studies in healthy younger and elderly adults as well as patients with neurological deficits indicate that post-learning rest supports memory consolidation compared to a period of distraction after learning (Brokaw et al. 2016; Cowan et al. 2004; Craig et al. 2015, 2016; Della Sala et al. 2005; Dewar et al. 2007, 2009, 2012; Mercer 2015). In line with this, we found that delayed memory performance in children aged 10-13 years profited more from a brief period of wakeful rest than watching short movies after encoding a word list.

It is an open question why resting after learning supports memory retention more than working on a (cognitively demanding) task. Views exist that memories are in a labile state after their acquisition and thus prone to interference. Interference after learning can diminish memory consolidation and as a consequence memory retention (Robertson 2012; Wixted 2004). Research indicates that similar (McGeoch 1931, 1933; Müller and Pilzecker 1900) and dissimilar/diversion/ non-specific interference (Dewar et al. 2007; Fatania and Mercer 2017) after learning can have detrimental effects on memory retention. For instance, retention of a word list can be interfered by encoding a second word list (Müller and Pilzecker 1900; McGeoch 1931), retention of a story or vocabularies can interfere with tasks like searching for errors in pictures (Dewar et al. 2012; Fatania and Mercer 2017), playing games (Brokaw et al.
Table 1 Overall and orderspecific memory performances in the rest condition and movies condition

\begin{tabular}{|c|c|c|c|c|c|c|}
\hline \multirow[b]{2}{*}{ Memory performance } & \multicolumn{2}{|c|}{ Overall $(N=24)$} & \multicolumn{2}{|c|}{ Condition order $1^{\mathrm{c}}(n=12)$} & \multicolumn{2}{|c|}{ Condition order $2^{\mathrm{d}}(n=12)$} \\
\hline & $M$ & $S D$ & $M$ & $S D$ & $M$ & $S D$ \\
\hline Immediate rest $\mathrm{t}^{\mathrm{a}}$ & .49 & .15 & .43 & .12 & .54 & .17 \\
\hline Immediate movies $^{\mathrm{a}}$ & .48 & .11 & .48 & .09 & .48 & .13 \\
\hline Delayed rest ${ }^{\mathrm{a}}$ & .37 & .19 & .30 & .16 & .44 & .19 \\
\hline Delayed movies $^{\mathrm{a}}$ & .26 & .15 & .30 & .13 & .21 & .16 \\
\hline Retention rest $^{\mathrm{b}}$ & .73 & .26 & 67 & .31 & .79 & .19 \\
\hline Retention movies ${ }^{\mathrm{b}}$ & .52 & .27 & .62 & .23 & .42 & .28 \\
\hline
\end{tabular}

$M$, mean; $S D$, standard deviation

${ }^{a}$ number of correctly recalled words divided by 15 (length of the word list)

${ }^{\mathrm{b}}$ number of correctly recalled words in the delayed recall test divided by the number of correctly recalled words in the immediate recall test

${ }^{\mathrm{c}}$ rest then movies condition

${ }^{\mathrm{d}}$ movies then rest condition 
2016), remembering faces (Mercer 2015), listening to the radio, watching videos, and detecting tones (Dewar et al. 2007). Wakeful resting, here defined as low amounts of external stimulus input and task-related mental activity (eyes closed, relaxed), seems to support the retention of memories. During this low interference state, labile memory representations seem to have a higher chance to get consolidated resulting in higher delayed memory performances (Mednick et al. 2011; Tambini et al. 2010; Karlsson and Frank 2009; van Kesteren et al. 2010).

Alternatively, it could be argued that higher retention scores in the rest compared to the movies condition are no evidence for memory consolidation, but rather the effect that retroactive interference is absent in the wakeful resting condition (Ecker and Lewandowsky 2012; Lewandowsky et al. 2012). For instance, according to the temporal-distinctiveness theory (Brown et al. 2007), retroactive interference effects are determined by temporal proximity. Accordingly, interfering material competes with the to-beremembered words during retrieval depending on their proximity in temporal space, i.e. the shorter the temporal interval, the higher the interference, the lower the memory performance (Ecker et al. 2015a). Based on our study design, we cannot rule out whether memory consolidation was disrupted or whether the movies condition interfered with the word list during retrieval.

A discussion of age-related differences in the impact of a brief period of wakeful rest after learning on memory retention (compared to a cognitive task delay period) should also be led based on the view that the brain is subject to age-related and developmental changes. Differences in the effect of a brief period of post-encoding wakeful rest in children and adults might be based on differences in the maturity of brain areas relevant for processing the task at hand. Task-relevant brain areas involved in, for instance, binding of information elements during encoding or protection of memory representations against interference may not be fully developed in children (e.g. prefrontal cortex, hippocampus; Riggins et al. 2018; Shing et al. 2010; Ofen et al. 2007; Keresztes et al. 2017). This might, in turn, result in memory representations of lower strength and/or higher susceptibility to interference (Darby and Sloutsky 2015). Low interference phases, like during wakeful resting, might thus support memory consolidation resulting in higher delayed memory performance when compared to a cognitive task delay period.

It is also conceivable that the disruption of rehearsal strategies in the movies condition led to lower delayed memory performances than in the resting condition. However, we assume that rehearsal played a minor role due to our finding of low rehearsal rates in both delay conditions and low relations between rehearsal rates and delayed memory performance. These results support recent findings in young adults indicating that intentional rehearsal during resting seems not to be a determining factor for memory retention (Dewar et al. 2014).

A limitation of our study is that we have no information on whether resting after learning supports memory retention also over the long term (e.g. days). Studies with healthy elderly adults and amnesic patients indicate that a memory supporting effect of resting persists up to 7 days (Alber et al. 2014; Dewar et al. 2012).

These 'long-term' resting effects were supported by a recent study of Martini et al. (2018a) in children aged 1314 years showing a higher memory retention in lower immediate memory performers over 7 days in a 10-min postencoding resting condition compared to a problem-solving condition.

Additionally, our study gives no information on memoryrelated developmental changes in the impact of watching movies after learning (for reviews about memory development across the life span see Hertzog and Shing 2010; Gathercole 1998). Investigations into developmental changes in the effect of wakeful resting are scarce. The study of Fatania and Mercer (2017) with children and adults showed that children profited from resting, while adults did not (Martini et al. 2017; Varma et al. 2017). This result, together with others (Darby and Sloutsky 2015), indicates that under specific conditions retroactive interference seems to be more detrimental in children than adults (but see also Howe 1995; Koppenaal et al. 1964).

Unexpectedly, based on the fact that we fully counterbalanced the rest condition and movies condition, our results indicate that the time point of resting might play a role. We showed similar retention performances when the rest condition was followed by the movies condition. Significantly higher retention performance was found when the movies condition was followed by the rest condition. Due to the low sample size per order of condition, our interpretations are limited. It is conceivable that consolidation of the first word list was disrupted by the second experimental condition (encoding and recall of the second word list followed by the respective delay condition). Given that the exact time course of consolidation is still unclear, it is conceivable that words needed more time to get stabilized, and consequently to become less prone to interference. This would be an interesting future research question, which should be conducted in view of a study by Dewar et al. (2009) in older amnesic patients and healthy older adults. They showed that memory retention of verbal material in amnesic patients was higher when post-encoding interference occurred at the end of a 9-min delay interval than when it occurred in the middle (3$6 \mathrm{~min})$ or at the beginning $(0-3 \mathrm{~min})$ of the interval. Investigating the optimal length of a resting phase and the optimal time point for resting (e.g. beginning or ending of a longer learning session) are interesting future research topics. 


\section{Conclusion}

We found that a brief period of wakeful resting after encoding new verbal information supported memory retention in children. Our results extend existing findings (Fatania and Mercer 2017; Experiment 1) in that we found the resting effect (i) in children aged 10-13 years (ii) with the implementation of a delay interference task close to children's everyday life activity (GSMA 2014; Ofcom 2017). Adding some minutes of wakeful rest to periods of intensive learning would be a cheap and quick intervention to increase memory performance and learning-related outcome in children. Identifying conditions under which wakeful resting after learning is effective as well as age-specific modulating factors for the resting effect (see Martini et al. 2018a, b) are important issues for future research.

Acknowledgements We gratefully acknowledge Julia Woelke's work on data collection and management for this study.

Funding Open access funding provided by University of Innsbruck and Medical University of Innsbruck.

\section{Compliance with Ethical Standards}

\section{Conflicts of Interest None.}

Ethical Approval All procedures performed in studies involving human participants were in accordance with the ethical standards of the institutional and/or national research committee and with the 1964 Helsinki declaration and its later amendments or comparable ethical standards. This article does not contain any studies with animals performed by any of the authors.

Informed Consent Informed consent was obtained from all individual participants included in the study.

Open Access This article is distributed under the terms of the Creative Commons Attribution 4.0 International License (http:// creativecommons.org/licenses/by/4.0/), which permits unrestricted use, distribution, and reproduction in any medium, provided you give appropriate credit to the original author(s) and the source, provide a link to the Creative Commons license, and indicate if changes were made.

\section{References}

Alber, J., Della Sala, S., \& Dewar, M. (2014). Minimizing interference with early consolidation boosts 7-day retention in amnesic patients. Neuropsychology, 28(5), 667-675. https://doi.org/10.1037/neu0000091.

Backhaus, J., Hoeckesfeld, R., Born, J., Hohagen, F., \& Junghanns, K. (2008). Immediate as well as delayed post learning sleep but not wakefulness enhances declarative memory consolidation in children. Neurobiology of Learning and Memory, 89(1), 76-80. https://doi.org/10.1016/j.nlm.2007.08.010.

Bauer, P. J., Van Abbema, D. L., \& de Haan, M. (1999). In for the short haul: Immediate and short-term remembering and forgetting by 20 - month-old children. Infant Behavior \& Development, 22(3), 321343. https://doi.org/10.1016/S0163-6383(99)00014-4.

Bigham, J. (1894). Memory. Studies from the Harvard psychological laboratory (II). Psychological Review, 1(5), 453-461.

Brokaw, K., Tishler, W., Manceor, S., Hamilton, K., Gaulden, A., Parr, E., et al. (2016). Resting state EEG correlates of memory consolidation. Neurobiology of Learning and Memory, 130, 17-25. https://doi.org/ 10.1016/j.nlm.2016.01.008.

Brown, G. D., Neath, I., \& Chater, N. (2007). A temporal ratio model of memory. Psychological Review, 114(3), 539-576. https://doi.org/10. 1037/0033-295x.114.3.539.

Cowan, N., Beschin, N., \& Della Sala, S. (2004). Verbal recall in amnesiacs under conditions of diminished retroactive interference. Brain, 127(4), 825-834. https://doi.org/10.1093/ brain/awh107.

Cowan, N., Elliott, E. M., Saults, J. S., Morey, C. C., Mattox, S., Hismjatullina, A., et al. (2005). On the capacity of attention: Its estimation and its role in working memory and cognitive aptitudes. Cognitive Psychology, 51(1), 42-100. https://doi.org/10.1016/j. cogpsych.2004.12.001.

Craig, M., Dewar, M., Della Sala, S., \& Wolbers, T. (2015). Rest boosts the long-term retention of spatial associative and temporal order information. Hippocampus, 25(9), 1017-1027. https://doi.org/10.1002/hipo.22424.

Craig, M., Wolbers, T., Harris, M. A., Hauff, P., Della Sala, S., \& Dewar, M. (2016). Comparable rest-related promotion of spatial memory consolidation in younger and older adults. Neurobiology of Aging, 48, 143-152. https://doi.org/10.1016/ j.neurobiolaging.2016.08.007.

Darby, K. P., \& Sloutsky, V. M. (2015). The cost of learning: Interference effects in memory development. Journal of Experimental Psychology: General, 144(2), 410-431. https://doi.org/10.1037/xge0000051.

Della Sala, S., Cowan, N., Beschin, N., \& Perini, M. (2005). Just lying there, remembering: Improving recall of prose in amnesic patients with mild cognitive impairment by minimising interference. Memory, 13(3-4), 435-440.

Deuker, L., Olligs, J., Fell, J., Kranz, T. A., Mormann, F., Montag, C., et al. (2013). Memory consolidation by replay of stimulus-specific neural activity. Journal of Neuroscience, 33(49), 19373-19383. https://doi.org/10.1523/jneurosci.0414-13.2013.

Dewar, M., Cowan, N., \& Della Sala, S. (2007). Forgetting due to retroactive interference: A fusion of Muller and Pilzecker's (1900) early insights into everyday forgetting and recent research on anterograde amnesia. Cortex, 43(5), 616-634

Dewar, M., Garcia, Y. F., Cowan, N., \& Della Sala, S. (2009). Delaying interference enhances memory consolidation in amnesic patients. Neuropsychology, 23(5), 627-634. https://doi.org/10.1037/ a0015568

Dewar, M., Alber, J., Butler, C., Cowan, N., \& Della Sala, S. (2012). Brief wakeful resting boosts new memories over the long term. Psychological Science, 23(9), 955-960. https://doi.org/10.1177/ 0956797612441220

Dewar, M., Alber, J., Cowan, N., \& Della Sala, S. (2014). Boosting long-term memory via wakeful rest: Intentional rehearsal is not necessary, consolidation is sufficient. PLoS One, 9(10), e109542. https://doi.org/10.1371/journal.pone.0109542.

Dudai, Y., Karni, A., \& Born, J. (2015). The consolidation and transformation of memory. Neuron, 88(1), 20-32. https://doi.org/10.1016/j. neuron.2015.09.004

Ecker, U. K. H., \& Lewandowsky, S. (2012). Computational constraints in cognitive theories of forgetting. [Perspective]. Frontiers in Psychology, 3(400), https://doi.org/10.3389/fpsyg.2012.00400. 
Ecker, U. K. H., Brown, G. D. A., \& Lewandowsky, S. (2015a). Memory without consolidation: Temporal distinctiveness explains retroactive interference. Cognitive Science, 39(7), 1570-1593. https://doi.org/10.1111/cogs.12214.

Ecker, U. K. H., Tay, J. X., \& Brown, G. D. (2015b). Effects of prestudy and poststudy rest on memory: Support for temporal interference accounts of forgetting. Psychonomic Bulletin \& Review, 22(3), 772-778. https://doi.org/10.3758/s13423-014-0737-8.

Fatania, J., \& Mercer, T. (2017). Nonspecific retroactive interference in children and adults. Advances in Cognitive Psychology, 13(4), 314 322. https://doi.org/10.5709/acp-0231-6.

Gathercole, S. E. (1998). The development of memory. Journal of Child Psychology and Psychiatry and Allied Disciplines, 39(1), 3-27.

GSMA (2014). Children's use of mobile phones. https://www.gsma.com/ publicpolicy/wp-content/uploads/2012/03/GSMA_Childrens_use of_mobile_phones_2014.pdf.

Helmstaedter, C., Lendt, M., \& Lux, S. (2001). Verbaler Lern- und Merkfähigkeitstest. Göttingen: Hogrefe.

Henderson, L., Weighall, A., Brown, H., \& Gareth Gaskell, M. (2012). Consolidation of vocabulary is associated with sleep in children. Developmental Science, 15(5), 674-687. https://doi.org/10.1111/j. 1467-7687.2012.01172.x.

Henderson, L., Weighall, A., Brown, H., \& Gaskell, G. (2013). Online lexical competition during spoken word recognition and word learning in children and adults. Child Development, 84(5), 1668-1685. https://doi.org/10.1111/cdev.12067.

Hertzog, C., \& Shing, Y. L. (2010). Memory development across the life span. In K. L. Fingerman, B. C. A. J. Smith, \& T. C. Antonucci (Eds.), Handbook of life-span development (pp. 299-330). New York: Springer Publishing Company.

Howe, M. L. (1995). Interference effects in young children's longterm retention. Developmental Psychology, 31(4), 579-596. https://doi.org/10.1037/0012-1649.31.4.579.

Karlsson, M. P., \& Frank, L. M. (2009). Awake replay of remote experiences in the hippocampus. Nature Neuroscience, 12(7), 913-918. https://doi.org/10.1038/nn.2344.

Keresztes, A., Bender, A. R., Bodammer, N. C., Lindenberger, U., Shing, Y. L., \& Werkle-Bergner, M. (2017). Hippocampal maturity promotes memory distinctiveness in childhood and adolescence. Proceedings of the National Academy of Sciences, 114(34), 92129217. https://doi.org/10.1073/pnas.1710654114.

Koppenaal, R. J., Krull, A., \& Katz, H. (1964). Age, interference, and forgetting. Journal of Experimental Child Psychology, 1(4), 360 375. https://doi.org/10.1016/0022-0965(64)90029-3.

Kurth, S., Jenni, O. G., Riedner, B. A., Tononi, G., Carskadon, M. A., \& Huber, R. (2010). Characteristics of sleep slow waves in children and adolescents. Sleep, 33(4), 475-480.

Lewandowsky, S., Ecker, U. K. H., Farrell, S., \& Brown, G. D. A. (2012). Models of cognition and constraints from neuroscience: A case study involving consolidation. Australian Journal of Psychology, 64(1), 37-45. https://doi.org/10.1111/j.1742-9536.2011.00042.x.

Martini, M., Riedlsperger, B., Maran, T., \& Sachse, P. (2017). The effect of post-learning wakeful rest on the retention of second language learning material over the long term. Current Psychology. https://doi.org/10.1007/s12144-017-9760-z.

Martini, M., Martini, C., Bernegger, C., \& Sachse, P. (2018a). Post-encoding wakeful resting supports the retention of new verbal memories in children aged 13-14 years. British Journal of Developmental Psychology. https://doi.org/10. 1111/bjdp.12267.

Martini, M., Martini, C., Maran, T., \& Sachse, P. (2018b). Effects of postencoding wakeful rest and study time on long-term memory performance. Journal of Cognitive Psychology, 30(5-6), 558-569. https://doi.org/10.1080/20445911.2018.1506457.

McGeoch, J. A. (1931). The influence of four different interpolated activities upon retention. Journal of Experimental Psychology, 14(4), 400.

McGeoch, J. A. (1933). Studies in retroactive inhibition: II. Relationships between temporal point of interpolation, length of interval, and amount of retroactive inhibition. The Journal of General Psychology, 9(1), 44-57. https://doi.org/10.1080/ 00221309.1933 .9920912$.

Mednick, S. C., Cai, D. J., Shuman, T., Anagnostaras, S., \& Wixted, J. T. (2011). An opportunistic theory of cellular and systems consolidation. Trends in Neurosciences, 34(10), 504-514. https://doi.org/10. 1016/j.tins.2011.06.003.

Mercer, T. (2015). Wakeful rest alleviates interference-based forgetting. Memory, 23(2), 127-137. https://doi.org/10.1080/ 09658211.2013 .872279 .

Müller, G. E., \& Pilzecker, A. (1900). Experimentelle Beiträge zur Lehre vom Gedächtnis. Zeitschrift für Psychologie, Ergänzungsband, 1, $1-300$.

Ofcom (2017). Children and parents: Media use and attitudes report. https://www.ofcom.org.uk/_data/assets/pdf_file/0020/108182/ children-parents-media-use-attitudes-2017.pdf.

Ofen, N., Kao, Y. C., Sokol-Hessner, P., Kim, H., Whitfield-Gabrieli, S., \& Gabrieli, J. D. (2007). Development of the declarative memory system in the human brain. Nature Neuroscience, 10(9), 1198-1205. https://doi.org/10.1038/nn1950.

Ohayon, M. M., Carskadon, M. A., Guilleminault, C., \& Vitiello, M. V. (2004). Meta-analysis of quantitative sleep parameters from childhood to old age in healthy individuals: Developing normative sleep values across the human lifespan. Sleep, 27(7), 1255-1273.

Peigneux, P., Orban, P., Balteau, E., Degueldre, C., Luxen, A., Laureys, S., et al. (2006). Offline persistence of memory-related cerebral activity during active wakefulness. PLoS Biology, 4(4), e100. https://doi.org/10.1371/journal.pbio.0040100.

Riggins, T., Geng, F., Botdorf, M., Canada, K., Cox, L., \& Hancock, G. R. (2018). Protracted hippocampal development is associated with age-related improvements in memory during early childhood. Neuroimage, 174, 127-137. https://doi.org/10.1016/j.neuroimage. 2018.03.009.

Robertson, E. M. (2012). New insights in human memory interference and consolidation. Current Biology, 22(2), R66-R71. https://doi.org/10.1016/j.cub.2011.11.051.

Schapiro, A. C., McDevitt, E. A., Rogers, T. T., Mednick, S. C., \& Norman, K. A. (2018). Human hippocampal replay during rest prioritizes weakly learned information and predicts memory performance. Nature Communications, 9(1), 3920. https:// doi.org/10.1038/s41467-018-06213-1.

Shing, Y. L., Werkle-Bergner, M., Brehmer, Y., Müller, V., Li, S.-C., \& Lindenberger, U. (2010). Episodic memory across the lifespan: The contributions of associative and strategic components. Neuroscience \& Biobehavioral Reviews, 34(7), 1080-1091. https://doi.org/10. 1016/j.neubiorev.2009.11.002.

Staresina, B. P., Alink, A., Kriegeskorte, N., \& Henson, R. N. (2013). Awake reactivation predicts memory in humans. Proceedings of the National Academy of Sciences of the United States of America, 110(52), 21159-21164. https://doi. org/10.1073/pnas.1311989110.

Tambini, A., Ketz, N., \& Davachi, L. (2010). Enhanced brain correlations during rest are related to memory for recent experiences. Neuron, 65(2), 280-290. https://doi.org/10.1016/j. neuron.2010.01.001. 
van Kesteren, M. T., Fernandez, G., Norris, D. G., \& Hermans, E. J. (2010). Persistent schema-dependent hippocampal-neocortical connectivity during memory encoding and postencoding rest in humans. Proceedings of the National Academy of Sciences of the United States of America, 107(16), 75507555. https://doi.org/10.1073/pnas.0914892107.

Varma, S., Takashima, A., Krewinkel, S., van Kooten, M., Fu, L., Medendorp, W. P., et al. (2017). Non-interfering effects of active post-encoding tasks on episodic memory consolidation in humans. Frontiers in Behavioral Neuroscience, 11, 54. https://doi.org/10.3389/fnbeh.2017.00054.

Wilhelm, I., Diekelmann, S., \& Born, J. (2008). Sleep in children improves memory performance on declarative but not procedural tasks. Learning and Memory, 15(5), 373-377. https://doi.org/10.1101/lm.803708.

Wilhelm, I., Prehn-Kristensen, A., \& Born, J. (2012). Sleep-dependent memory consolidation-what can be learnt from children? Neuroscience and Biobehavioral Reviews, 36(7), 1718-1728. https://doi.org/10.1016/j.neubiorev.2012.03.002.

Wixted, J. T. (2004). The psychology and neuroscience of forgetting. Annual Review of Psychology, 55, 235-269. https://doi.org/10. 1146/annurev.psych.55.090902.141555.

Publisher's note Springer Nature remains neutral with regard to jurisdictional claims in published maps and institutional affiliations. 